\title{
Incidence of mandibular fractures in Eastern part of Libya
}

\author{
Rafa-Abdelsalam Elgehani ${ }^{1}$, Maraai-Idris Orafi ${ }^{2}$ \\ ${ }^{1}$ BDS, MDentSc, FFDRCSI, MOSRCSEd. Associate Professor \\ ${ }^{2}$ BDS, MFDSRCSEd. Senior registrar \\ Department of oral and maxillofacial surgery. Al Arab Medical University, Benghazi. Libya
}

Correspondence:

Department of oral and maxillofacial surgery,

Post box no 9504

Al Arab Medical University,

Benghazi

Libya

maraaiorafi@yahoo.com

Received: $14 / 09 / 2008$

Accepted: 20/05/2009

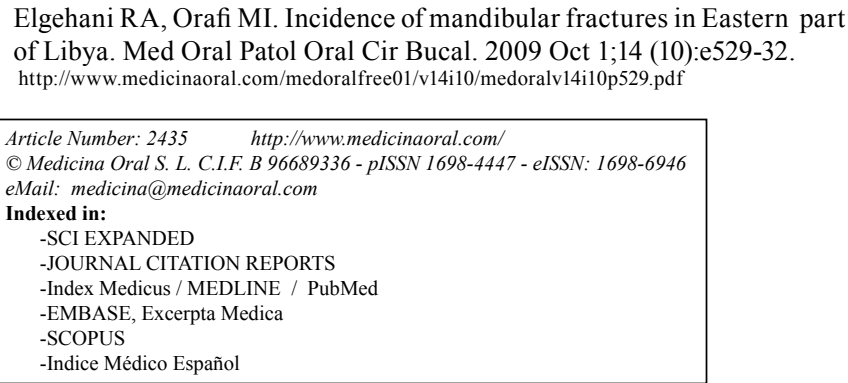

\begin{abstract}
The objective of this retrospective study is to evaluate the incidence of mandibular fractures in the eastern part of Libya and to present our experience in treating this type of facial fracture. We analyzed factors such as the incidence of age, sex, time distribution, cause and site of the fracture and the associated injuries in 493 patients presenting a total of 666 mandibular fractures. These patients were treated at Al-Jala Trauma Hospital, Benghazi-Libya between 2000 and 2006. The results were obtained from 432 males and 61 females, for which the ages ranged from 8 months to 72 years. The maximum number of the patients was recorded in 2004, and the busiest month was May. The most common cause of fracture was road traffic accidents and the most common site was the parasymphysis. Among those treated with closed reduction were 241 patients, whereas 201 patients were treated with open reduction. In conclusion, we found that the results were similar to most studies from developing countries and were in contrast to other studies. This may be due factors such as geography, socioeconomic trends, religion, road traffic legislation and seasons, which differ from one country to another. The period during which there was an embargo in Libya also appears to have affected the results.
\end{abstract}

Key words: Incidence, RTA, facial, mandible, fractures.

\section{Introduction}

The position, prominence, anatomic configuration, mobility and less bone support of the mandible make it one of the most frequent facial bones to be fractured (1).

The mandibular fracture account for $36 \%$ to $54 \%$ of all fractures in the maxillofacial region, followed by the maxilla (46\%), the zygoma (27\%), and the nasal bones $(19.5 \%)$.

It can be caused by traumatic or pathological mecha- nisms. The traumatic causes comprise; road traffic accident (RTA), interpersonal violence (IPV), falls, sport injuries, and industrial trauma (1). The RTA appear to be the leading cause of mandibular fracture in the developing countries where as in the developed countries the IPV seem to be the main cause $(1,2)$. This is influenced by the geography, socioeconomic trends, religion, road traffic legislation, and seasons which are different from one country to another. 


\section{Patients and Methods}

A retrospective study of 493 patients presented with 666 mandibular fractures treated at Oral and Maxillofacial Surgery Department, Faculty of Dentistry, Al-Arab medical university and Al-Jala Trauma Hospital, Benghazi-Libya, between a period of 2000 and 2006. Factors considered were sex, age, time distribution, cause and site of the fracture, treatment modalities and associated injuries. The data were collected from patient files in the archives reviewing the records and radiographs.

\section{Results}

There were $432(87.6 \%)$ male patients and 61 (12.3\%) female patients. Male to female (M:F) ratio was $7.1: 1$ (Fig. 1).

The age group was ranging from 8 months to 72 years. The youngest and oldest patients were females and they were victims of RTA. The etiology of the mandibular fractures were as following; RTA $(n=188)$, IPV $(n=138)$, fall $(n=114)$, occupational $(n=26)$, sport $(n=20)$, gunshot $(n=3)$, pathological $(n=2)$, animal attack $(n=1)$, and tyre explosion $(n=1)$.
Table 1. Distribution of fractures according to age group.

\begin{tabular}{|c|c|c|}
\hline Age group & $\begin{array}{l}\text { Number of } \\
\text { patients }\end{array}$ & Percent \% \\
\hline $0-10$ & 47 & 9.5 \\
\hline $11-20$ & 100 & 20.2 \\
\hline $21-30$ & 238 & 48.2 \\
\hline $31-40$ & 80 & 16.2 \\
\hline $41-50$ & 17 & 3.4 \\
\hline $51-60$ & 10 & 2 \\
\hline$\geq 61$ & 1 & 0.2 \\
\hline Total & $\mathbf{4 9 3}$ & $\mathbf{1 0 0}$ \\
\hline
\end{tabular}

Distribution of fractures according to age group and time are shown in tables 1,2 respectively. The total number of the mandibular fractures was 666 in 493 patients (mean 1.4 fracture/mandible). The findings revealed 306 patients with single fracture line, and 187 patients with multiple fracture lines.



Fig. 1. Distribution of fractures according to sex.

Table 2. Distribution of fractures according to time.

\begin{tabular}{|c|c|c|c|c|c|c|c|c|}
\hline Months/years & $\mathbf{2 0 0 0}$ & $\mathbf{2 0 0 1}$ & $\mathbf{2 0 0 2}$ & $\mathbf{2 0 0 3}$ & $\mathbf{2 0 0 4}$ & $\mathbf{2 0 0 5}$ & $\mathbf{2 0 0 6}$ & Total \\
\hline January & 3 & 12 & 2 & 2 & 10 & 2 & 2 & 33 \\
\hline February & 3 & 5 & 1 & 9 & 5 & 4 & 2 & 28 \\
\hline March & 4 & 7 & 5 & 4 & 9 & 5 & 2 & 36 \\
\hline April & 3 & 6 & 3 & 7 & 12 & 6 & 6 & 43 \\
\hline May & 9 & 6 & 8 & 1 & 9 & 13 & 10 & 56 \\
\hline June & 9 & 6 & 6 & 5 & 8 & 9 & 9 & 52 \\
\hline July & 3 & 5 & 4 & 8 & 8 & 12 & 6 & 46 \\
\hline August & 1 & 6 & 4 & 15 & 7 & 5 & 5 & 43 \\
\hline September & 3 & 10 & 4 & 7 & 11 & 5 & 10 & 50 \\
\hline October & 9 & 4 & 8 & 5 & 8 & 5 & 5 & 44 \\
\hline November & 3 & 5 & 4 & 10 & 9 & 2 & 3 & 36 \\
\hline December & 1 & 1 & 3 & 9 & 2 & 4 & 6 & 26 \\
\hline Total & $\mathbf{5 1}$ & $\mathbf{7 3}$ & $\mathbf{5 2}$ & $\mathbf{8 2}$ & $\mathbf{9 8}$ & $\mathbf{7 1}$ & $\mathbf{6 6}$ & $\mathbf{4 9 3}$ \\
\hline
\end{tabular}


The most common fracture line was in the parasymphysis region $(n=180)$ followed by the angle $(n=145)$ then the body region $(n=128)$, condyle $(n=124)$, symphysis $(n=37)$, dentoalveolar $(n=29)$, ramus $(n=13)$, and the coronoid $(n=9)$. We had one patient with an unusual fracture type in which large segment was lost from right primary first molar to left one due to gun shot injury. The parasymphysis and angle were the most common multiple fractures followed by the parasymphysis and subcondylar areas.

Eight patients were admitted to our department with history of fall following epileptic fits. All of them were male, with age ranging from 21 to 39 years. This entire group was treated by open reduction and internal fixation (ORIF).

The total number of the patients with associated injuries are 174 patients distributed as follows; maxillary fractures $(n=35)$, zygoma fracture $(n=31)$, nasal bone fractures $(n=13)$, multiple facial fractures $(n=12)$, head injuries $(n=23)$, orthopaedic injuries $(n=27)$, facial laceration $(n=16)$, abdominal/ thoracic injuries $(n=17)$.

$48.9 \%(n=241)$ of our patients were treated by closed reduction. Out of this, 205 patients $(41.6 \%)$ were treated by intermaxillary fixation (IMF), 17 patients $(3.4 \%)$ were treated by acrylic splint with circummandibular wiring (AS-CMW), most of them were children, and 19 patients $(3.9 \%)$ with isolated dentoalveolar fracture (DA) were treated by single arch fixation using arch bars and direct dental wiring.

201 patients $(41 \%)$ were managed by ORIF using monocortical miniplates except in 3 patients (gun-shot) who required reconstruction plates. 40 patients $(8.1 \%)$ presented with crack or undisplaced subcondylar fractures with acceptable occlusion and were kept on soft diet and observation. 11 patients ( $2 \%$ ) left the hospital against the medical advice (LAMA), without treatment (Fig. 2).

\section{Discussion}

In our study the incidence of male sex was more than female sex which is consistent with most of the studies (1-4). M: F ratio was 7.1:1 which is high compared to other studies $(2,3)$ in which the ratio was approximately 3:1. Subhashraj et al. (5) reported a ratio of 5.1:1, M:F. The high ratio in our country might because less participation of females in the out-door and social life, driving and sport activities.

Very high ratio (out of 124 patients 123 males to 1 female) was reported in India by Chambers et al. (6).

The incidence of mandibular fracture was higher in age group between 21 to 30 years.

This finding consistent with previous studies $(1,3,4,7-$ $10)$ and differed with Sakr et al. study (2) which revealed higher incidence in first decade $(29 \%)$.

In the developed countries the IPV appear to be the most common cause of mandibular fracture, where as in developing countries the RTA appear to be the most common cause $(1,2)$. This is may be due to deficiency in road traffic legislations, car maintenance, poor roads and bad driving. The IPV appear to be less this may be because of less alcohol consumption and drug abuse in the Islamic countries.

In Libya there are no bars, pubs and night clubs. During the leisure time the people usually go for picnic in the rural areas particularly the Green Mountain which is beautiful spot in the eastern part of Libya. Here the roads are curved, poorly maintained and don't have traffic signs and street lights. All these factors contribute to the high incidence of RTA in this part of Libya.

In this study the RTA was the leading cause of mandibular fracture. This is similar to the other studies $(2,11,12)$. The second most common cause in our study was IPV, followed by falls. Others reported the IPV as the main cause $(3,4,7,13,14)$.



$\square$ treatment

Fig. 2. Distribution of fractures according to treatment. 
In Sakr et al. (2) the second cause was falls followed IPV. The sport related injuries seem to be increasingly implicated in the causes of maxillofacial injuries (15).

The gunshot was the leading cause reported in study conducted in India during the Second World War (6). Emshoff et al. (15) reported 1.5 fracture/mandible which approximates our finding, where as Subhashraj et al. (5) reported 1.9 fracture/mandible.

Confirming the previous reports $(1,5,16)$, we found that the most common site of fracture was the parasymphysis, followed by angle of the mandible. This is probably because of long canine root and unerupted wisdom tooth. In other studies the most common site was in the angle region $(2,3,13)$. The least site of fracture in our study was the coronoid process, similar to the other studies $(2,5,6)$. Rapidis et al. (17) reported that coronoid process fracture constitute $0.6 \%-4.7 \%$ of all facial bone fractures, making the coronoid process the least frequent fractured portion of the mandible. However Kirk et al. (3) demonstrated the dentoalveolar fractures as least occurrence.

The most common site of mandibular fracture was the body in other study (8). The parasymphysis and the angle were the most common multiple fracture sites in our findings. In Subhashraj et al. (1) the usual combination of fractures was parasymphysis and condyle followed by body and angle.

Regarding seasonal distribution, the largest number of patients was on year 2004 ( $\mathrm{n}=98)$, and the busiest month was May followed by June. Usually this is vacation time in which picnic, traveling and other outdoor activities increases subsequently rising the incidence of the fractures. January was the busiest month in Sakr et al. study (2). In approximation with our finding, Kirk et al. (3) demonstrated $(60.1 \%)$ of their patients treated with closed reduction and $(30.9 \%)$ of the patients by ORIF, Sakr et al. (2) reported (48\%) of their patients treated with closed reduction (IMF or single arch fixation) and (36.2\%) patients treated with ORIF which agreed with our study. In Schon et al. study (4) 105 patients of their 114 patients were managed by ORIF and 9 patients treated with closed reduction.

ORIF proffers a number of advantages when compared with traditional methods using IMF. Although the ORIF does have potential disadvantages like injury to the vital structures and devitalization of the bone segments (18). Lamphier et al. (13) found closed reduction to have a significantly lower complication rate compared with open reduction. We treated $41.6 \%$ of our patients with IMF because of high number of the patients presented to our surgery with lack of facilities due to prohibited import during embargo period of Libya and also we preferred to treat patients with comminuted fractures conservatively to avoid devitalization of small fragments of the bone preserving the plates for other patients.

The most common associated injury in this study was the maxillary fractures followed by zygomatic fracture, this is due to anatomical proximity of these bones to the mandible. In agreement with our results Sakr et al. (2) mentioned the mid-facial fractures as the most common associated injuries with mandibular fracture. Others $(1,3)$ found the head injuries mostly associated with the mandibular fracture. Kirk et al. (5) reported the maxillary fractures as the third common associated injury.

After the embargo period of Libya, the road traffic legislations improved and the companies started maintaining the roads so they have lights and traffic signs. Hopefully these will reduce the incidence of the RTA in the next few years.

\section{References}

1. Subhashraj K, Nandakumar N, Ravindran C. Review of maxillofacial injuries in Chennai, India: a study of 2748 cases. Br J Oral Maxillofac Surg. 2007;45:637-9.

2. Sakr K, Farag IA, Zeitoun IM. Review of 509 mandibular fractures treated at the University Hospital, Alexandria, Egypt. Br J Oral Maxillofac Surg. 2006;44:107-11.

3. Fridrich KL, Pena-Velasco G, Olson RA. Changing trends with mandibular fractures: a review of 1,067 cases. J Oral Maxillofac Surg. 1992;50:586-9.

4. Schön R, Roveda SI, Carter B. Mandibular fractures in Townsville, Australia: incidence, aetiology and treatment using the $2.0 \mathrm{AO} / \mathrm{ASIF}$ miniplate system. Br J Oral Maxillofac Surg. 2001;39:145-8.

5. Subhashraj K, Ramkumar S, Ravindran C. Pattern of mandibular fractures in Chennai, India. Br J Oral Maxillofac Surg. 2008;46:126-7.

6. Chambers IG, Scully C. Mandibular fractures in India during the Second World War (1944 and 1945): analysis of the Snawdon series. Br J Oral Maxillofac Surg. 1987;25:357-69.

7. Adi M, Ogden GR, Chisholm DM. An analysis of mandibular fractures in Dundee, Scotland (1977 to 1985). Br J Oral Maxillofac Surg. 1990;28:194-9

8. Khalil AF, Shaladi OA. Fractures of the facial bones in the eastern region of Libya. Br J Oral Surg. 1981;19:300-4.

9. Van Hoof RF, Merkx CA, Stekelenburg EC. The different patterns of fractures of the facial skeleton in four European countries. Int J Oral Surg. 1977;6:3-11.

10. Vetter JD, Topazian RG, Goldberg MH, Smith DG. Facial fractures occurring in a medium-sized metropolitan area: recent trends. Int $\mathrm{J}$ Oral Maxillofac Surg. 1991;20:214-6.

11. Adams CD, Januszkiewcz JS, Judson J. Changing patterns of severe craniomaxillofacial trauma in Auckland over eight years. Aust N Z J Surg. 2000;70:401-4

12. Tay AG, Yeow VK, Tan BK, Sng K, Huang MH, Foo CL. A review of mandibular fractures in a craniomaxillofacial trauma centre. Ann Acad Med Singapore. 1999;28:630-3.

13. Lamphier J, Ziccardi V, Ruvo A, Janel M. Complications of mandibular fractures in an urban teaching center. J Oral Maxillofac Surg. 2003;61:745-9.

14. Oikarinen K, Ignatius E, Kauppi H, Silvennoinen U. Mandibular fractures in northern Finland in the 1980s--a 10-year study. Br J Oral Maxillofac Surg. 1993;31:23-7.

15. Emshoff R, Schöning H, Röthler G, Waldhart E. Trends in the incidence and cause of sport-related mandibular fractures: a retrospective analysis. J Oral Maxillofac Surg. 1997;55:585-92.

16. Peled M, Laufer D, Helman J, Gutman D. Treatment of mandibular fractures by means of compression osteosynthesis. J Oral Maxillofac Surg. 1989;47:566-9.

17. Rapidis AD, Papavassiliou D, Papadimitriou J, Koundouris J, Zachariadis N. Fractures of the coronoid process of the mandible. An analysis of 52 cases. Int J Oral Surg. 1985;14:126-30.

18. Ochs MW, Tucker MR. Current concepts in management of facial trauma. J Oral Maxillofac Surg. 1993;51:42-55. 